\title{
Efficient oxidation of cinnamon oil to natural benzaldehyde over $\beta$-cyclodextrin-functionalized MWCNTs
}

\author{
Zujin Yang a,c, Xia Zhang d, Yanxiong Fang d, Zebao Rui a,c,*, Hongbing Ji b,c,\# \\ a School of Chemical Engineering and Technology, Sun Yat-sen University, Guangzhou 510275, Guangdong, China \\ b School of Chemistry, Sun Yat-sen University, Guangzhou 510275, Guangdong, China \\ c Huizhou Research Institute of Sun Yat-sen University, Huizhou 516216, Guangdong, China \\ d Faculty of Chemical Engineering and Light Industry, Guangdong University of Technology, Guangzhou 510006, Guangdong, China
}

\section{A R T I C L E I N F O}

\section{Article history:}

Received 20 July 2016

Accepted 1 September 2016

Published 5 December 2016

\section{Keywords:}

$\beta$-cyclodextrin

Cinnamon oil

Selective oxidation

Benzaldehyde

Multi-walled carbon nanotube

Synergistic effect

\begin{abstract}
A B S T R A C T
We have designed and prepared $\beta$-cyclodextrin $(\beta$-CD)-functionalized multi-walled nanotubes (MWCNTs-g-CD) for the oxidation of cinnamon oil to natural benzaldehyde under aqueous conditions. The synergistic effect of combining MWCNTs with $\beta$-CD led to a remarkable increase in the performance of the MWCNTs-g-CD for the catalytic oxidation of cinnamaldehyde, which exhibited $95 \%$ cinnamaldehyde conversion and $85 \%$ selectivity to natural benzaldehyde with a short reaction time of $10 \mathrm{~min}$. The MWCNTs-g-CD also exhibited outstanding recyclability with good stability, showing no discernible decrease in their catalytic activity over five reaction cycles.
\end{abstract}

(C) 2016, Dalian Institute of Chemical Physics, Chinese Academy of Sciences. Published by Elsevier B.V. All rights reserved.

\section{Introduction}

Benzaldehyde $(\mathrm{BzH})$ is the second most commonly used flavor compound in the world, with a wide range of important applications in the food and drink, cosmetics and pharmaceutical industries [1-5]. Increasing concerns surrounding food quality has led to a growing demand for natural benzaldehyde. The natural benzaldehyde used in commercial applications is mainly obtained by the aqueous hydrolysis of natural cinnamon oil, which contains more than $80 \%$ cinnamaldehyde $[6,7]$. However, the widespread application of this process has been limited by the poor aqueous solubility of cinnamon oil and the low selectivity of this transformation towards natural benzaldehyde [8-10]. The oxidation of cinnamaldehyde in the liquid phase therefore represents a promising route for the manufacture of natural benzaldehyde under mild conditions [11]. However, the biggest challenge to realizing this approach is the availability of an effective catalyst, especially economically viable noble metal-free catalysts.

Cyclodextrins (CDs) are an important class of cyclic oligosaccharides that contain 6-8 D-glucose units linked together by $\alpha$-1,4-glucose bonds, which are called $\alpha$-, $\beta$ - and $\gamma$-CDs, respectively. The central cavity of a CD system provides a hydrophobic space in which a suitable guest molecule can be sequestered

\footnotetext{
* Corresponding author. Tel: +86-20-84113663; E-mail: ruizebao@mail.sysu.edu.cn

\# Corresponding author. Tel: +86-20-84113658; E-mail: jihb@mail.sysu.edu.cn

This work was supported by the National Natural Science Foundation of China (21376279, 21276102, 21425627), Guangdong Technology Research Center for Synthesis and Separation of Thermosensitive Chemicals (2015B090903061), the Fundamental Research Funds for the Central Universities (14lgpy28), and Guangzhou Science and Technology Plan Projects (2014J4100125).

DOI: 10.1016/S1872-2067(16)62543-3 | http://www.sciencedirect.com/science/journal/18722067 | Chin. J. Catal., Vol. 37, No. 12, December 2016
} 
under aqueous conditions. CDs are known to form inclusion complexes with a wide range of compounds, especially aromatic compounds [12-14]. Considerable research efforts have been directed towards the development of CDs capable of mimicking natural enzymes with high catalytic activity and substrate selectivity during the last decade. Among them, $\beta-C D$ has been widely used to mediate a broad range of organic transformation under aqueous conditions, including oxidation, reduction, ring opening and hydrolysis reactions [15-20]. However, $\beta$-CD is soluble in water and must be immobilized on an appropriate solid support so that it can be readily recycled. $\beta$-CD was recently immobilized on cellulose and chitosan, and the resulting supported systems were applied to the catalytic oxidation of cinnamaldehyde under aqueous conditions [21-24]. The results revealed that $\beta-C D$ and the functional groups of the support acted synergistically to allow for the oxidation of cinnamaldehyde. However, from an industrial production perspective, the application of these catalysts could be limited by their low mechanical strength and poor durability towards successive reaction cycles.

Carbon nanotubes (CNTs) have also been studied extensively as catalysts (or supports) and adsorbent materials for liquid phase reaction-adsorption systems because of their unique properties, including their excellent electrical and thermal conductivity, good chemical stability and recyclability, environmental acceptability and low cost [25-28]. Several studies have shown that CNTs are effective adsorbents than activated carbon for the removal of organic pollutants from aqueous solutions because of their excellent adsorption capacity $[29,30]$. CNTs have also been used as metal-free catalysts in numerous reactions, including the oxidative dehydrogenation of aromatic hydrocarbons and alkanes, the reduction of oxygen, the oxidation of hydrocarbons and phenols, and the decomposition of ammonia [31-34]. Furthermore, CNTs have been used to catalyze the oxidation of benzyl alcohol to benzaldehyde using molecular oxygen as an oxidant $[35,36]$. There have been numerous reports in the literature aimed at modifying the surfaces of CNTs by the introduction of specific functional groups to improve their performance as catalysts and adsorbents [37-39]. As part of our ongoing interest in such materials, we report herein the development of surface-modified CNT system bearing $\beta$-CDs as a high performance catalyst for the oxidation of cinnamaldehyde. To the best of our knowledge, this study represents the first reported example of the systematic evaluation of $\beta$-CD-functionalized multi-walled CNTs (MWCNTs) as a recyclable heterogeneous catalyst for the oxidation of cinnamon oil for industrial application.
The main goal of this work was to design $\beta$-CD grafted MWCNTs (MWCNTs-g-CD) for the oxidation of cinnamon oil to natural benzaldehyde under aqueous conditions (Scheme 1). It was investigated that the MWCNTs-g-CD would allow for the supramolecular recognition of $\beta-C D$, as well as showing good adsorption and chemical stability properties. The resulting catalyst was initially evaluated for the oxidation of cinnamaldehyde using hydrogen peroxide as the terminal oxidant under the mild reaction conditions. A plausible mechanism was proposed for the oxidation of cinnamaldehyde. The MWCNTs-g-CD exhibited enhanced catalytic activity comparison with the MWCNTs and $\beta-C D$ in isolation, which was attributed to the occurrence of a synergistic effect between $\beta$-CD and the MWCNTs.

\section{Experimental}

\subsection{Materials}

MWCNTs were purchased from Shenzhen Nanotech Port Co., Ltd (Shenzhen, China). $\beta$-CD (>99\%) was purchased from Shanghai Boao Biotechnology (Shanghai, China). Cinnamaldehyde ( $>99 \%$ ) was obtained from Sinopharmacy Chemical Reagent (Shanghai, China). All of the other chemicals used in this study were purchased as the analytical grade and used without further purification. All of the aqueous solutions were prepared using Milli-Q water under ambient conditions.

\subsection{Preparation of MWNTs-g-CD}

MWNTs were purified and oxidized according to a previously reported procedure [40]. Briefly, MWCNTs (200 mg) were added to a solution of $\mathrm{HNO}_{3}(3 \mathrm{~mol} / \mathrm{L}, 20 \mathrm{~mL})$, and the resulting mixture was agitated under ultrasonic irradiation at $25^{\circ} \mathrm{C}$ for $30 \mathrm{~min}$. The mixture was then heated at $120^{\circ} \mathrm{C}$ with an agitation speed of $120 \mathrm{r} / \mathrm{min}$ for $24 \mathrm{~h}$. Upon completion of the reaction, the mixture was cooled to room temperature and the solids were separated by centrifugation ( $1 \mathrm{~min}$ ), washed to neutral $\mathrm{pH}$ with distilled water and dried under vacuum to give MWNTs-COOH. A small portion of this material $(60 \mathrm{mg})$ was dispersed in $\mathrm{SOCl}_{2}(25 \mathrm{~mL})$ under sonication conditions for 30 min in the presence of DMF $(1 \mathrm{~mL})$. The mixture was then heated at $80{ }^{\circ} \mathrm{C}$ under nitrogen overnight. Upon completion of the reaction, the solvent and excess $\mathrm{SOCl}_{2}$ were removed under reduced pressure to give the acyl chloride-functionalized MWNTs (MWNTs-COCl). This material was immediately dispersed in DMF $(10 \mathrm{~mL})$ under sonication conditions for $5 \mathrm{~min}$
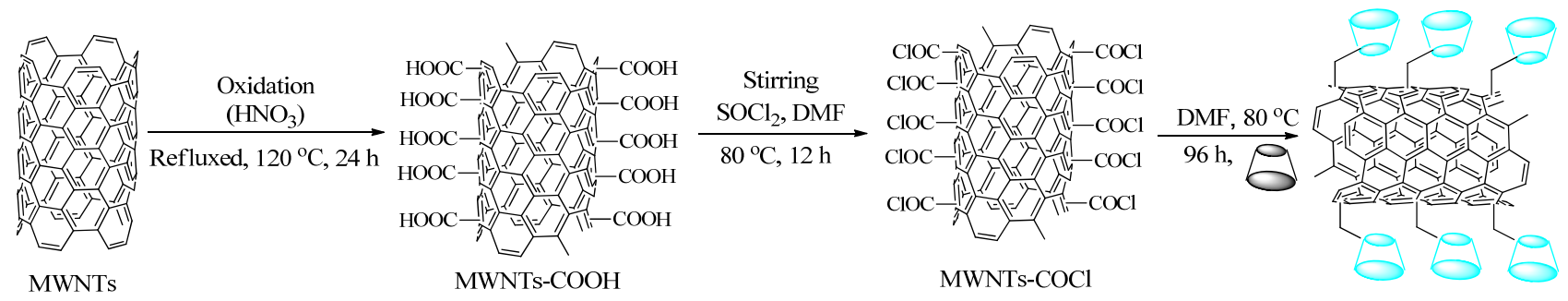

MWCNTs-g-CD

Scheme 1. Schematic diagram of the MWCNTs-g-CD preparation process. 
before being treated with $\beta$-CD (1 mmol) and triethylamine $(0.5 \mathrm{~mL})$. The resulting mixture was heated in an oil bath at 80 ${ }^{\circ} \mathrm{C}$ for $96 \mathrm{~h}$. The product of this reaction was washed repeatedly with deionized water to remove all of the free $\beta$-CD. The washed product was then dried in an oven at $80^{\circ} \mathrm{C}$ for $24 \mathrm{~h}$ to give the MWCNTs-g-CD.

\subsection{Catalyst characterization}

Fourier transform infrared (FTIR) spectra were recorded on a TENSOR 37 FTIR spectrometer (Bruker, Ettlingen, Germany) as $\mathrm{KBr}$ disks for wavelengths in the range of $4000-400 \mathrm{~cm}^{-1}$. Thermogravimetric analysis (TGA) was performed on a STA-449C thermal analysis system (Netzsch, Selb, Germany). The TGA measurements (weight loss) were performed using dried samples under $\mathrm{N}_{2}$ with a flow rate of $50 \mathrm{~mL} / \mathrm{min}$. The temperature of each measurement was increased from room temperature to $800{ }^{\circ} \mathrm{C}$ at a rate of $10{ }^{\circ} \mathrm{C} / \mathrm{min}$. The X-ray crystal structure of the catalyst was measured by X-ray diffraction (XRD) analysis using a D/max-2200/PC X-ray diffractometer (Rigaku, Tokyo, Japan) equipped with a $\mathrm{Cu} K \alpha$ radiation source $(\lambda=1.54056 \AA)$. Raman spectra were recorded using a Lab-RAM Aramaic micro Raman spectrometer (Renishaw Diagnostics, Gloucestershire, UK) with an excitation wavelength of $514.5 \mathrm{~nm}$ to investigate the surface structures of the MWCNTs and MWCNTs-g-CD. Transmission electron microscopy (TEM, S-520, JEOL, Tokyo, Japan) was used to determine the surface morphology and the particle size characteristics of the catalysts. The BET specific surface areas were measured using an ASAP 2020 accelerated surface area and porosimetry analyzer (Micromeritics, Norcross, GA, USA).

\subsection{Selective oxidation of cinnamaldehyde}

The catalytic oxidation of cinnamaldehyde was performed according to a previously reported procedure [41]. Typically, a mixture of the catalyst $(60 \mathrm{mg})$ and cinnamaldehyde $(1 \mathrm{mmol})$ in deionized water was added to a $100 \mathrm{~mL}$ three necked flask fitted with a reflux condenser and magnetic stirrer. The mixture was then heated at $60{ }^{\circ} \mathrm{C}$ for $0.5 \mathrm{~h}$, before being treated with a solution of $\mathrm{H}_{2} \mathrm{O}_{2}$ (2.5 mL, $30 \mathrm{wt} \%$ ) containing $\mathrm{NaHCO}_{3}(2$ mmol), which was added to the reaction mixture in a dropwise manner under stirring. Samples were taken at appropriate intervals and extracted with ethyl acetate $(5 \mathrm{~mL})$ before being centrifuged. The supernatants were analyzed and identified by gas chromatography-mass spectrometry (GC-MS) using an Agilent 7890B gas chromatograph (Agilent, Santa Clara, CA, USA) equipped with a HP-5 column ( $30 \mathrm{~m} \times 0.25 \mathrm{~mm}$ id, 0.25 $\mu \mathrm{m})$, which was coupled to an Agilent HP5977A mass spectrometer. The reproducibilities for these data were determined to be within $5 \%$.

\subsection{Computational chemistry calculations}

All of the calculations were performed using the DMol3 method in version 8.0 of the Materials Studio software (Accelrys Inc., San Diego, CA, USA) [42]. The geometries and com- plexation energies of the host, guest and host-guest inclusion complex were optimized using a local density approximation (LDA) in the Perden-Wang (PWC) form at the Double Numerical plus d-functions (DND) basis set level $[23,41]$. Each complex was minimized in energy in an aqueous environment. The binding energy (BE) values were expressed as follows:

$$
\mathrm{BE}=E_{\mathrm{C}}-E_{\mathrm{G}}-E_{\mathrm{H}}
$$

where $E_{\mathrm{C}}$ is the total energy of the inclusion complex, $E_{\mathrm{G}}$ is the sum total energy of the guest, and $E_{\mathrm{H}}$ is the total energy of the host. The MWCNTs and cinnamaldehyde were selected as the host and model guest molecules, respectively.

\section{Results and discussion}

\subsection{Catalyst characterization}

\subsubsection{Raman analysis}

The Raman spectra of the MWCNTs and MWCNTs-g-CD are shown in Fig. 1. The main peaks in the spectra at 1350 and $1590 \mathrm{~cm}^{-1}$ were attributed to the disordered (D mode) and the graphite (G mode) structures of the MWCNTs, respectively. The $\mathrm{G}$ and $\mathrm{D}$ bands usually represent the $E_{2 \mathrm{~g}}$ phonons of the $s p^{2}$ atoms and the breathing mode of the $k$-point phonons with $\mathrm{A}_{1 \mathrm{~g}}$ symmetry, respectively. The intensity ratio $\left(I_{D} / I_{G}\right)$ of the $D$ and $\mathrm{G}$ bands in graphitic materials can be used to evaluate the size of $s p^{2}$ domains [43]. The $I_{\mathrm{D}} / I_{\mathrm{G}}$ ratios of the MWCNTs and MWCNTs-g-CD were determined to be 0.96 and 1.21 , respectively, indicating that the $s p^{2}$ domains were larger in the latter of these two systems. These results therefore indicated that the degree of disorder on the surfaces of the MWCNTs increased after the grating of the $\beta$-CD molecules.

\subsubsection{TEM analysis}

TEM images of the MWCNTs and MWCNTs-g-CD are presented in Fig. 2. It showed that the MWCNTs were tubular in shape with a smooth surface, vertical sidewalls and a diameter in the range of 10-30 nm. The MWCNTs-g-CD exhibited a more compact stacking morphology. The diameters of the MWCNTs-g-CD were in the range of $20-40 \mathrm{~nm}$, which is larger than that of the MWCNTs. This difference in the diameters was attributed to the grafting of the $\beta$-CD molecules to the surfaces of the MWCNTs, which is consistent with previous studies

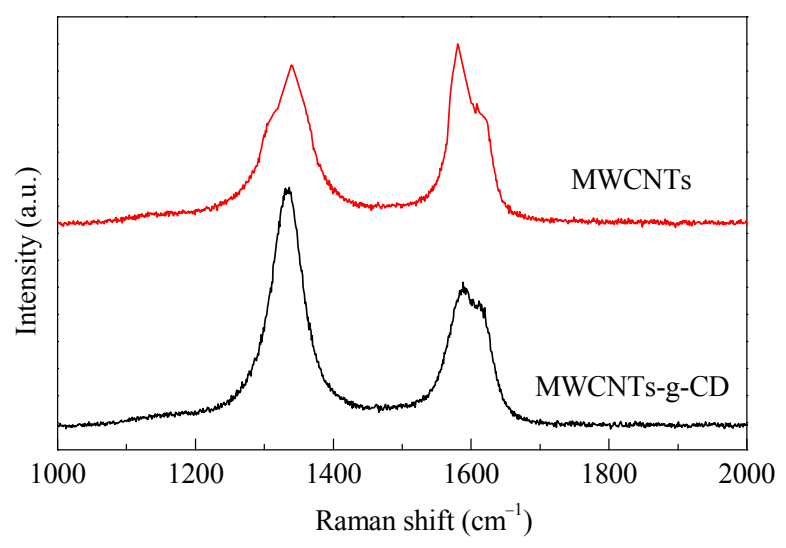

Fig. 1. Raman spectra of MWCNTs and MWCNTs-g-CD. 


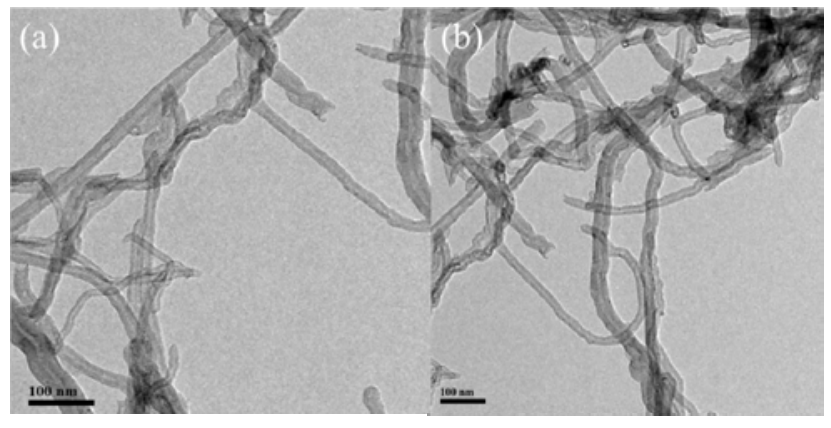

Fig. 2. TEM images of MWCNTs (a) and MWCNTs-g-CD (b).

$[44,45]$. Furthermore, several porous interspaces were observed on the surfaces of the MWCNTs-g-CD, which could enhance the catalytic activity of this system.

\subsubsection{FTIR analysis}

The FTIR spectra of the MWCNTs, $\beta$-CD and MWCNTs-g-CD are shown in Fig. 3. The MWCNTs contained two prominent absorption bands at 3400 and $1630 \mathrm{~cm}^{-1}$, which were attributed to the stretching vibrations of the water molecules adsorbed on the surfaces of the MWCNTs and the $\mathrm{C}=0$ stretching vibrations of the quinone groups on the surface, respectively [46]. The FTIR spectrum of $\beta$-CD contained major absorption bands at $3400 \mathrm{~cm}^{-1}$ (-OH stretching vibrations), $2910 \mathrm{~cm}^{-1}\left(-\mathrm{CH}_{2}\right.$ stretching vibrations), $1630 \mathrm{~cm}^{-1}$ (H-O-H bending), $1164 \mathrm{~cm}^{-1}$ (C-O stretching vibrations) and $1030 \mathrm{~cm}^{-1}$ (C-O-C stretching vibrations). The FTIR spectrum of the MWCNTs-g-CD clearly showed several functional groups belonging to $\beta$-CD, including $-\mathrm{CH}_{2}\left(2910 \mathrm{~cm}^{-1}\right), \mathrm{C}-\mathrm{O}\left(1164 \mathrm{~cm}^{-1}\right)$ and $\mathrm{C}-\mathrm{O}-\mathrm{C}\left(1030 \mathrm{~cm}^{-1}\right)$ groups, which indicated that the grafting of $\beta$-CD to the MWCNTs was successful. Notably, the intensity of the peak observed at $3400 \mathrm{~cm}^{-1}$ for the MWCNTs-g-CD was greater than that of the MWCNTs, which could be attributed to there being more hydroxyl groups in the former of these two species because of the $\beta$-CD molecules. Moreover, the peak observed at $950 \mathrm{~cm}^{-1}$ in the MWCNTs-g-CD is characteristic of an $\alpha-(1,4)$ glucopyranose [47]. The new peak at $1735 \mathrm{~cm}^{-1}$ was due to ester groups, indicating that the carboxylic acid groups in MWCNTs-COOH reacted with hydroxyl groups of $\beta$-CD during

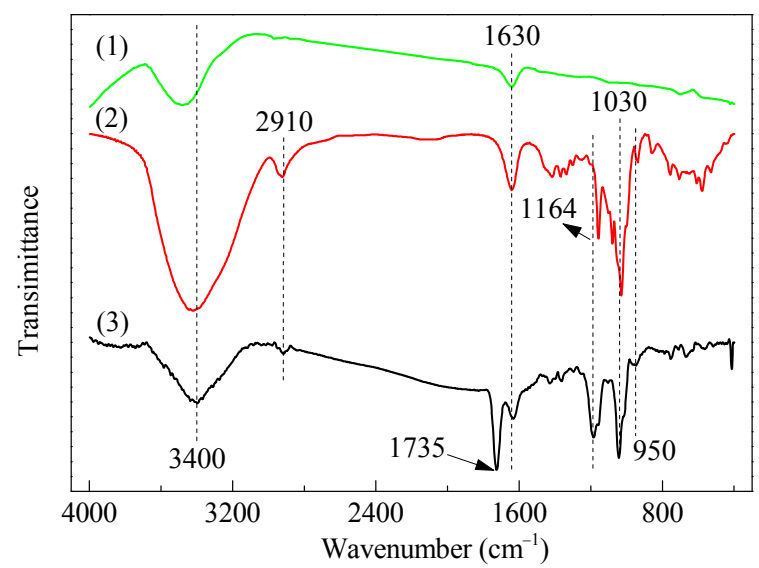

Fig. 3. FTIR spectra of MWCNTs (1), $\beta-C D(2)$, and MWCNTs-g-CD (3).

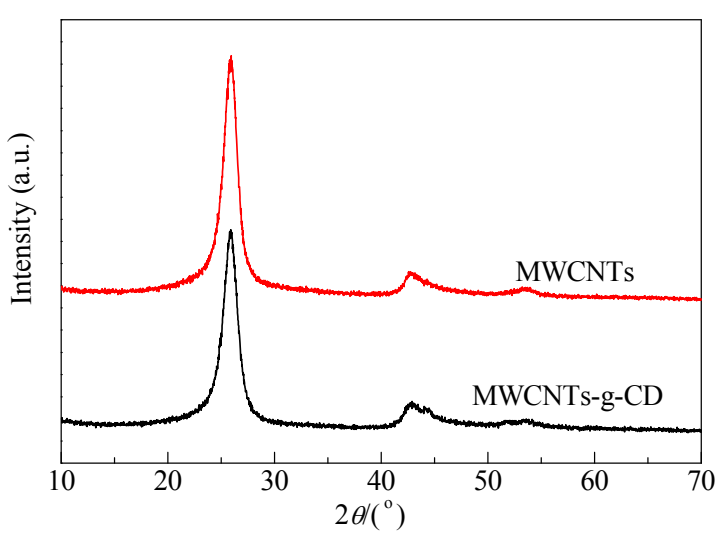

Fig. 4. XRD patterns of MWCNTs and MWCNTs-g-CD.

the grafting process [48]. Therefore, the results clearly suggest that $\beta$-CD is successfully immobilized on the surface of MWCNTs.

\subsubsection{XRD and BET analysis}

The XRD patterns of the MWCNTs and MWCNTs-g-CD are shown in Fig. 4 . Both of these materials gave peaks at $26^{\circ}, 44^{\circ}$ and $54^{\circ}$, which are characteristic of MWCNTs [49]. These results indicated that the $\beta$-CD molecules had been grafted onto the surfaces of the MWCNTs in a way that did not interfere with their structural framework. Similar results to these have been reported elsewhere in the literature [50]. The grafting of $\beta-C D$ onto the surface of the MWCNTs led to a decrease in the BET surface area from $101 \mathrm{~m}^{2} / \mathrm{g}$ (MWCNTs) to $22 \mathrm{~m}^{2} / \mathrm{g}$ (MWCNTs-g-CD), as well as a decrease in the pore volume from 0.4806 to $0.1284 \mathrm{~cm}^{3} / \mathrm{g}$. Similar results were also observed in our previous study [51]. The average pore diameters of the MWCNTs and MWCNTs-g-CD were determined to be 23.2 and $19.2 \mathrm{~nm}$, respectively.

\subsubsection{TG analysis}

TG curves for the MWCNTs, $\beta$-CD and MWCNTs-g-CD are shown in Fig. 5. The TG curve for the MWCNTs showed two separate weight loss steps. The first weight loss occurred at $100{ }^{\circ} \mathrm{C}$, which was caused by dehydration, whereas the second

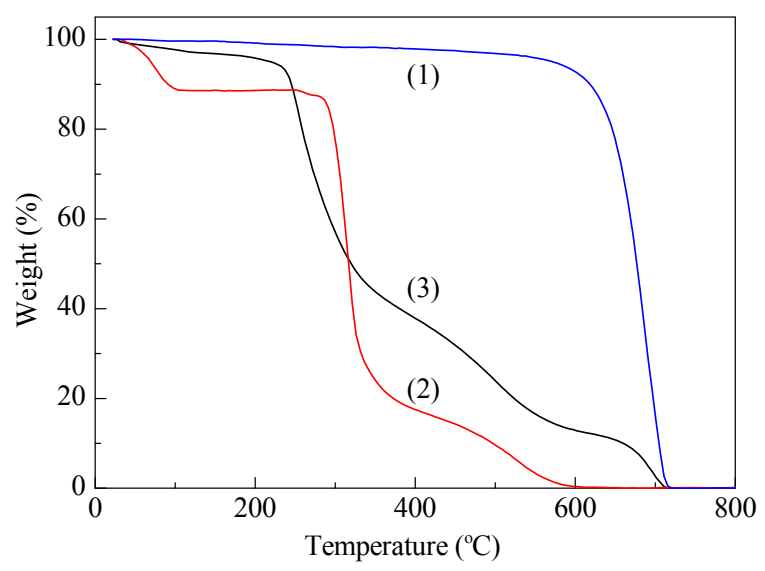

Fig. 5. TGA curves of MWNTs (1), $\beta$-CD (2) and MWCNTs-g-CD (3). 
weight loss occurred at $450-700{ }^{\circ} \mathrm{C}$, which was attributed to the decomposition of the MWCNTs. The TG curve of $\beta$-CD showed three degradation stages, including two weight loss steps at $50-110$ and $320-450{ }^{\circ} \mathrm{C}$, which were attributed to the evaporation of water adsorbed by $\beta-C D$ and the thermal decomposition of $\beta$-CD, respectively. The third weight loss step occurred at temperatures above $450{ }^{\circ} \mathrm{C}$ and was attributed to a carbonization process. The MWCNTs-g-CD showed a weight loss at $100{ }^{\circ} \mathrm{C}$, which was attributed to the loss of moisture and solvents incorporated in the polymer. The TG curve of MWCNTs-g-CD also showed weight losses at 280-450 and $450-700{ }^{\circ} \mathrm{C}$ corresponding to the decomposition of $\beta-\mathrm{CD}$ and the oxidation of the MWCNTs and the $\beta$-CD residues, respectively. Based on these TGA results, the weight percentage of surface grafted $\beta$-CD was estimated to be around $40 \%$ in the MWCNTs-g-CD. This result is consistent with previously findings [52].

\subsection{Catalytic performance of MWCNTs- $g-C D$}

A comparison of the catalytic performances of the MWCNTs, $\beta$-CD and MWCNTs-g-CD for the oxidation of cinnamaldehyde is shown in Fig. 6. A blank reaction was also conducted without any catalyst, which gave a low benzaldehyde yield of only $16 \%$ after $3 \mathrm{~h}$. MWCNTs alone cannot effectively promote the oxidation of cinnamaldehyde. The addition of $\beta$-CD was beneficial for the reaction, affording a cinnamaldehyde conversion of $72 \%$ after $3 \mathrm{~h}$ with a benzaldehyde selectivity of $62 \%$, which is consistent with previous results from the literature [21,23,41]. Among these catalysts, MWCNTs-g-CD was found to be the most effective, achieving a cinnamaldehyde conversion of $95 \%$ with a benzaldehyde selectivity of $85 \%$ after a reaction time of 10 min. These results clearly show that $\beta$-CD and MWCNTs were acting synergistically to allow for the efficient oxidation of cinnamaldehyde.

Fig. 7 shows the effects of several different parameters on

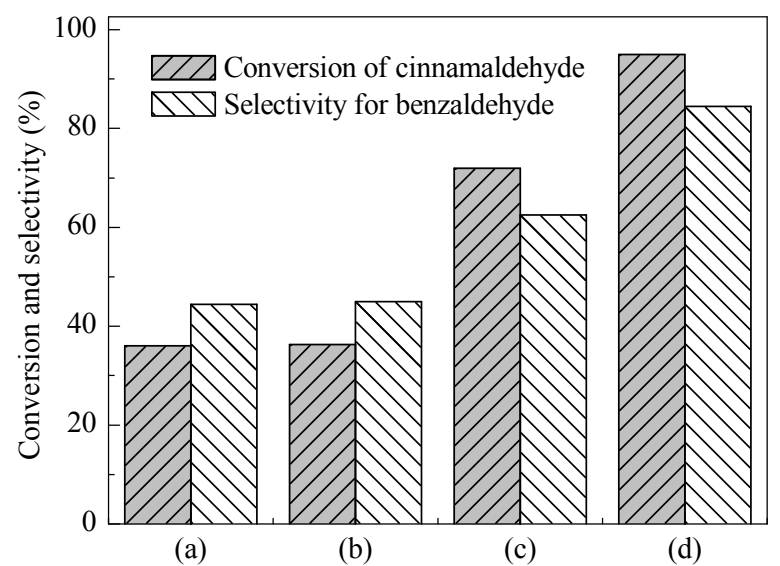

Fig. 6. Performance comparison over various catalysts. (a) Blank test, $30 \mathrm{wt} \% \mathrm{H}_{2} \mathrm{O}_{2}$ (2.5 mL), $\mathrm{NaHCO}_{3}(2 \mathrm{mmol}), 3 \mathrm{~h}$; (b) MWNTs (100 mg), 30 wt $\% \mathrm{H}_{2} \mathrm{O}_{2}$ (2.5 mL), $\mathrm{NaHCO}_{3}(2 \mathrm{mmol}$ ), $3 \mathrm{~h}$; (c) $\beta$-CD ( $1 \mathrm{mmol}$ ), $30 \mathrm{wt} \%$ $\mathrm{H}_{2} \mathrm{O}_{2}$ (4 mL), $\mathrm{NaHCO}_{3}$ (2.5 mmol), 3 h; (d) MWCNTs-g-CD (100 mg), 30 wt $\% \mathrm{H}_{2} \mathrm{O}_{2}(2.5 \mathrm{~mL}), \mathrm{NaHCO}_{3}(2 \mathrm{mmol}), 10 \mathrm{~min}$. Reaction conditions: cinnamaldehyde (1 mmol), $\mathrm{H}_{2} \mathrm{O}(25 \mathrm{~mL}), 60^{\circ} \mathrm{C}$. the outcome of the oxidation of cinnamaldehyde, including the reaction time, reaction temperature, amount of MWCNTs-g-CD, amount of $\mathrm{H}_{2} \mathrm{O}_{2}$ and amount of $\mathrm{NaHCO}_{3}$. It is noteworthy that the agitation speed also had an impact on this reaction (Fig. 7 (a)). Cinnamaldehyde conversions of $19.7 \%, 58.5 \%$ and $74.2 \%$ were achieved in the solution phase for agitation speeds of 0,100 , and $200 \mathrm{r} / \mathrm{min}$, respectively, after a reaction time of 12 min. At a low agitation speed, the conversion of cinnamaldehyde would be dependent on the low transfer rate of the oxidant from the aqueous phase into the solid-liquid phase. Higher agitation speeds would enhance the extent of the contact between the two phases and the performance of the catalyst. Agitation speeds of 300 and $400 \mathrm{r} / \mathrm{min}$ resulted in cinnamaldehyde conversions of $93.0 \%$ and $98.2 \%$, respectively, after $12 \mathrm{~min}$. However, further increases in the agitation speed did not result in further increases in the cinnamaldehyde conversion, indicating that the mass transfer was no longer driving this process. An agitation speed of $400 \mathrm{r} / \mathrm{min}$ was therefore selected as the optimum agitation speed to eliminate the effects of the liquid-solid mass transfer. This value was used to evaluate the other parameters. The conversion of cinnamaldehyde over the MWCNTs-g-CD increased with increasing reaction time and reached $95 \%$ after a reaction time of $10 \mathrm{~min}$. The selectivity to benzaldehyde for this reaction remained in the region of $85 \%$ from 1 to $10 \mathrm{~min}$. A slight decrease was observed in the selectivity when the reaction time was increased to 12 min most likely because of the deep oxidation of benzaldehyde. These results demonstrated that the optimal reaction time for this transformation was 10 min, which is much shorter than those reported for other cinnamaldehyde oxidation systems $[21-23,41]$, thereby highlighting the excellent performance of MWCNTs-g-CD. The cinnamaldehyde conversion and selectivity to benzaldehyde increased from $38 \%$ and $53 \%$ in the absence of MWCNTs-g-CD to $95 \%$ and $85 \%$, respectively, following the addition of $100 \mathrm{mg}$ of MWCNTs-g-CD at $60^{\circ} \mathrm{C}$ over $3 \mathrm{~h}$ (Fig. $7(\mathrm{c})$ ). This result indicated that the MWCNTs-g-CD played an important role in the oxidation of cinnamaldehyde. However, the addition of an excess of the MWCNTs-g-CD (e.g., $120 \mathrm{mg}$ ) led to a decrease in the benzaldehyde selectivity, which is attributed to the oxidation of benzaldehyde to benzoic acid $[21,23]$.

The effect of the amount of $\mathrm{H}_{2} \mathrm{O}_{2}$ on the performance of the MWCNTs-g-CD for the oxidation of cinnamaldehyde was also evaluated (Fig. 7(d)). The cinnamaldehyde conversion and selectivity to benzaldehyde increased from $14 \%$ and $45.7 \%$ in the absence of $\mathrm{H}_{2} \mathrm{O}_{2}$ to $95 \%$ and $85 \%$, respectively, following the addition of $2.5 \mathrm{~mL} \mathrm{H}_{2} \mathrm{O}_{2}$ at $60{ }^{\circ} \mathrm{C}$ over $3 \mathrm{~h}$. However, further increasing the amount of $\mathrm{H}_{2} \mathrm{O}_{2}$ to $3 \mathrm{~mL}$ led to a decrease in the benzaldehyde selectivity to $80 \%$. Based on the stoichiometry, the molar ratio of $\mathrm{H}_{2} \mathrm{O}_{2}$ to cinnamaldehyde was $1: 1$. In practice, a small excess of $\mathrm{H}_{2} \mathrm{O}_{2}$ was used in this reaction to overcome the losses encountered as a consequence of the decomposition of $\mathrm{H}_{2} \mathrm{O}_{2}$ at high temperatures. Notably, the oxygen released during the decomposition of $\mathrm{H}_{2} \mathrm{O}_{2}$ would have no impact on the oxidation of cinnamaldehyde [22,23]. Based on these results, $2.5 \mathrm{~mL}$ of $\mathrm{H}_{2} \mathrm{O}_{2}$ was selected as the optimum amount for this reaction. Although $\mathrm{H}_{2} \mathrm{O}_{2}$ is an oxygen-rich, environmentally 

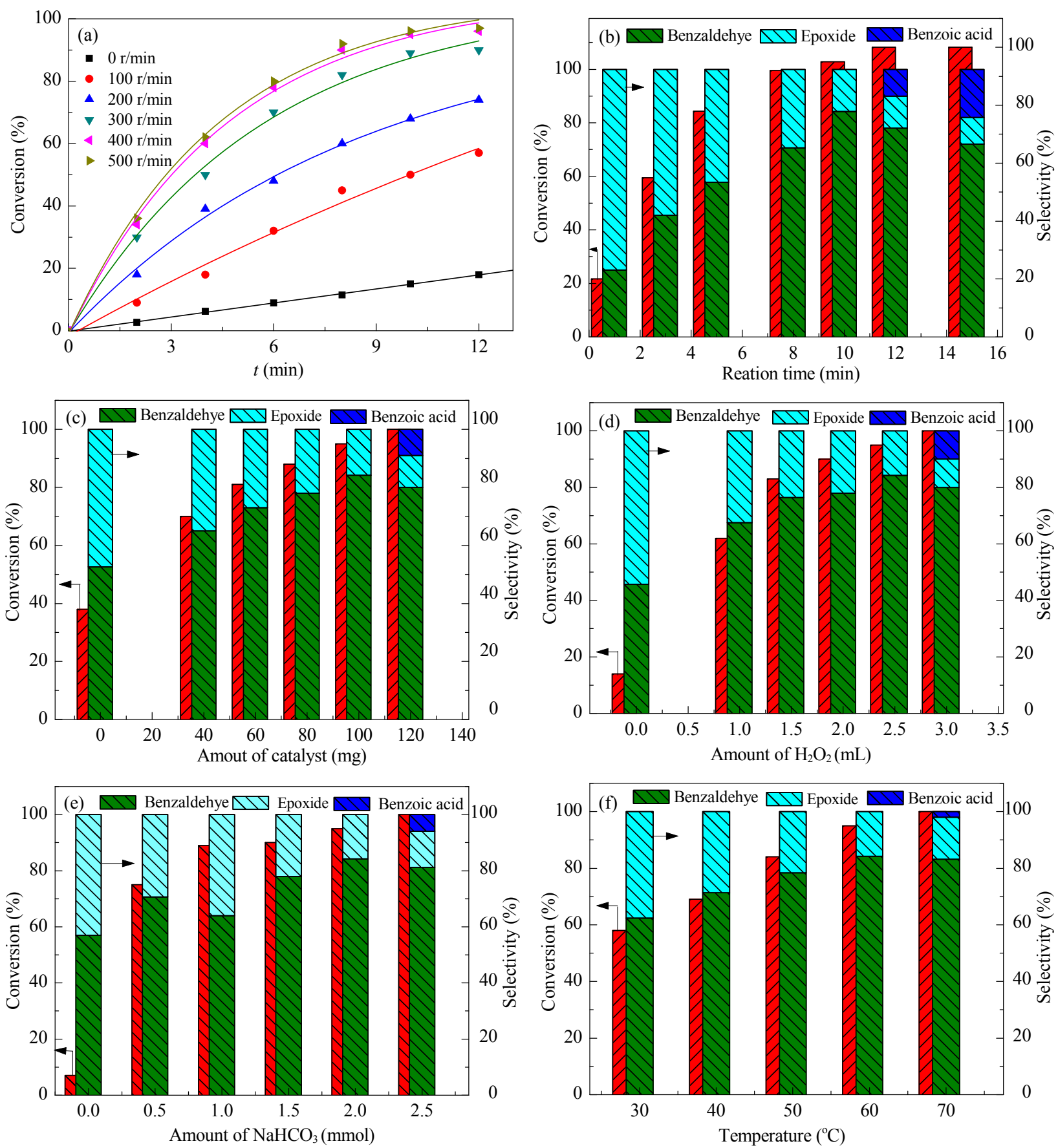

Fig. 7. (a) Effect of agitation speed under the conditions: cinnamaldehyde $(1 \mathrm{mmol}), \mathrm{MWCNTs}-\mathrm{g}-\mathrm{CD}(100 \mathrm{mg}), \mathrm{NaHCO}_{3}(2 \mathrm{mmol}), \mathrm{H}_{2} \mathrm{O}_{2}(2.5 \mathrm{~mL}, 30$ wt $\%), 60^{\circ} \mathrm{C}, 12 \mathrm{~min}$; (b) Effect of reaction time under the conditions: cinnamaldehyde (1 mmol), MWCNTs-g-CD (100 mg), $\mathrm{NaHCO}_{3}(2 \mathrm{mmol}), \mathrm{H}_{2} \mathrm{O}_{2}$ (2.5 mL, $30 \mathrm{wt} \%), 60^{\circ} \mathrm{C}$; (c) Effect of the amount of MWCNTs-g-CD employed under the conditions: cinnamaldehyde (1 mmol), $\mathrm{NaHCO}_{3}(2 \mathrm{mmol})$, $\mathrm{H}_{2} \mathrm{O}_{2}$ (2.5 mL, $\left.30 \mathrm{wt} \%\right), 60^{\circ} \mathrm{C}, 10 \mathrm{~min}$; (d) Effect of the amount of $\mathrm{H}_{2} \mathrm{O}_{2}$ employed under the conditions: cinnamaldehyde (1 mmol), MWCNTs-g-CD $(100 \mathrm{mg}), \mathrm{NaHCO}_{3}(2 \mathrm{mmol}), 60{ }^{\circ} \mathrm{C}, 10 \mathrm{~min}$; (e) Effect of the amount of $\mathrm{NaHCO}_{3}$ employed under the conditions: cinnamaldehyde (1 mmol), MWCNTs-g-CD (100 mg), $\mathrm{H}_{2} \mathrm{O}_{2}(2.5 \mathrm{~mL}, 30 \mathrm{wt} \%), 60^{\circ} \mathrm{C}, 10 \mathrm{~min}$; (f) Effect of reaction temperature under the conditions: cinnamaldehyde (1 mmol), MWCNTs-g-CD (100 mg), $\mathrm{H}_{2} \mathrm{O}_{2}(2.5 \mathrm{~mL}, 30 \mathrm{wt} \%), \mathrm{NaHCO}_{3}(2 \mathrm{mmol}), 10 \mathrm{~min}$.

friendly oxidant, which generates water as its only byproduct, it is a slow-acting oxidant in the absence of activation. Richardson et al. [53-55] reported a new method for activating $\mathrm{H}_{2} \mathrm{O}_{2}$ with bicarbonate ions. The treatment of $\mathrm{H}_{2} \mathrm{O}_{2}$ with bicarbonate ions resulted in the formation of peroxymonocarbonate ions $\left(\mathrm{HCO}_{4}^{-}\right)$, which effectively oxidized cinnamaldehyde to produce benzaldehyde [22,23]. As shown in Fig. 7(e), the cinnamalde- hyde conversion and benzaldehyde selectivity were $7 \%$ and $57 \%$, respectively, when the reaction was conducted in the absence of $\mathrm{NaHCO}_{3}$. Notably, the addition of $\mathrm{NaHCO}_{3}(2 \mathrm{mmol})$ led to a considerable improvement in the cinnamaldehyde conversion to $95 \%$, as well as an increase in the benzaldehyde selectivity to $85 \%$, indicating that $\mathrm{NaHCO}_{3}$ played a crucial role in the oxidation of cinnamaldehyde. Furthermore, increasing 
Table 1

Performance comparison among various $\beta$-CD based catalysts for the oxidation of cinnamaldehyde to benzaldehyde.

\begin{tabular}{|c|c|c|c|c|c|}
\hline Catalyst & $\begin{array}{l}\text { Conversion } \\
(\%)\end{array}$ & $\begin{array}{l}\text { Selectivity } \\
\quad(\%)\end{array}$ & $\begin{array}{l}\text { Reaction } \\
\text { time (min) }\end{array}$ & Conditions & Ref. \\
\hline MWCNTs-g-CD & 95 & 84.5 & 10 & $\begin{array}{c}\text { Cinnamaldehyde (1 mmol), MWCNTs-g-CD }(100 \mathrm{mg}), \mathrm{H}_{2} \mathrm{O}_{2}(2.5 \mathrm{~mL}, 30 \mathrm{wt} \%), \\
\mathrm{NaHCO}_{3}(2 \mathrm{mmol}), \mathrm{H}_{2} \mathrm{O}(25 \mathrm{~mL}), 60^{\circ} \mathrm{C}\end{array}$ & This work \\
\hline$\beta$-CD-CTS & 96 & 78.0 & 150 & $\begin{array}{c}\text { Cinnamaldehyde }(1 \mathrm{mmol}), \beta \text {-CD-CTS }(100 \mathrm{mg}), \mathrm{H}_{2} \mathrm{O}_{2}(4 \mathrm{~mL}, 30 \mathrm{wt} \%) \\
\mathrm{NaHCO}_{3}(2.5 \mathrm{mmol}), \beta \text {-CD }(1 \mathrm{mmol}), \mathrm{H}_{2} \mathrm{O}(25 \mathrm{~mL}), 60^{\circ} \mathrm{C}\end{array}$ & [21] \\
\hline$\beta-\mathrm{CDP}$ & 99 & 63.0 & 150 & $\begin{array}{c}\text { Cinnamaldehyde }(1 \mathrm{mmol}), \beta-\mathrm{CDP}(2 \mathrm{~g}), \mathrm{H}_{2} \mathrm{O}_{2}(4 \mathrm{~mL}, 30 \mathrm{wt} \%) \\
\mathrm{NaHCO}_{3}(1.5 \mathrm{mmol}), \mathrm{H}_{2} \mathrm{O}(25 \mathrm{~mL}), 60^{\circ} \mathrm{C}, 600 \mathrm{r} / \mathrm{min}\end{array}$ & [22] \\
\hline$\beta$-CDP & 92 & 62.0 & 120 & $\beta$-CDP $(1 \mathrm{~g}), \mathrm{HClO}(4 \mathrm{~mL}, 7.5 \mathrm{wt} \%), \mathrm{H}_{2} \mathrm{O}(25 \mathrm{~mL}), 70^{\circ} \mathrm{C}$ & [23] \\
\hline$\beta$-CDCP & 95 & 71.0 & 180 & $\begin{array}{c}\text { Cinnamaldehyde }(1 \mathrm{mmol}), \beta \text {-CDCP }(1 \mathrm{~g}), \mathrm{H}_{2} \mathrm{O}_{2}(4 \mathrm{~mL}, 30 \mathrm{wt} \%) \\
\mathrm{NaHCO}_{3}(2 \mathrm{mmol}), \mathrm{H}_{2} \mathrm{O}(25 \mathrm{~mL}), 70^{\circ} \mathrm{C}\end{array}$ & [24] \\
\hline 2-HP- $\beta$-CDCP & 97 & 83.5 & 60 & $\begin{array}{l}\text { Cinnamaldehyde (1 mmol), 2-HP- } \beta \text {-CDCP }(0.4 \mathrm{~g}), \mathrm{H}_{2} \mathrm{O}_{2}(2 \mathrm{~mL}, 30 \mathrm{wt} \%), \\
\mathrm{Na}_{2} \mathrm{CO}_{3}(1.5 \mathrm{mmol}), \mathrm{H}_{2} \mathrm{O}(25 \mathrm{~mL}), 60^{\circ} \mathrm{C}\end{array}$ & [41] \\
\hline
\end{tabular}

the amount of $\mathrm{NaHCO}_{3}$ to $2.5 \mathrm{mmol}$ led to further a increase in the cinnamaldehyde conversion to $100 \%$. However, this increase was accompanied by a decrease in the benzaldehyde selectivity to $80 \%$, which was caused by the oxidation of benzaldehyde to benzoic acid. Taken together, these results show that the addition of an appropriate amount of $\mathrm{NaHCO}_{3}$ is necessary for the reaction.

The reaction temperature also had a pronounced effect on the oxidation of cinnamaldehyde (Fig. 7(f)). For example, increasing the reaction temperature increased the cinnamaldehyde conversion and benzoic acid selectivity but led to a decrease in the benzaldehyde selectivity. The optimal reaction temperature for the oxidation of cinnamaldehyde was therefore set as $60^{\circ} \mathrm{C}$, which represents a compromise between the benzaldehyde selectivity and cinnamaldehyde conversion.

The performance characteristics of the MWCNTs- $\beta$-CD were evaluated under the optimized conditions and the results were compared with those of several other $\beta$-CD-based catalysts from the literature (Table 1). The results revealed that the MWCNTs- $\beta$-CD developed in the current study performed comparably or better than the other systems in terms of the cinnamaldehyde conversion and benzaldehyde selectivity. The MWCNTs- $\beta-C D$ also required much shorter reaction times then the other $\beta$-CD-based catalysts, thereby highlighting the excellent catalytic performance of the MWCNTs- $\beta$-CD for the oxidation of cinnamaldehyde. However, the MWCNTs- $\beta$-CD could decompose over time leading to a decrease in their catalytic activity, and small changes in the crystallinity of this material could go undetected by XRD. To evaluate this possibility, we conducted a series of experiments to assess the reusability of the catalyst, which is an important index for assessing the practical application of a catalytic system. Given that the benzaldehyde product of this reaction is soluble in ethyl acetate, which

\section{Table 2}

Cyclic stability test of MWCNTs-g-CD for the oxidation of cinnamaldehyde to benzaldehyde.

\begin{tabular}{lcccccc}
\hline Cycle & 1 & 2 & 3 & 4 & 5 & 6 \\
\hline Conversion (\%) & 95.0 & 94.8 & 94.2 & 93.8 & 93.1 & 90.2 \\
Selectivity (\%) & 84.5 & 84.0 & 84.0 & 83.8 & 82.9 & 78.6 \\
\hline Reaction
\end{tabular}

Reaction conditions: cinnamaldehyde derivative (1 $\mathrm{mmol})$, MWCNTs-g-CD (100 mg), $\mathrm{H}_{2} \mathrm{O}_{2}(2.5 \mathrm{~mL}, 30 \mathrm{wt} \%), \mathrm{NaHCO}_{3}$ (2 mmol), $\mathrm{H}_{2} \mathrm{O}(25 \mathrm{~mL}), 60^{\circ} \mathrm{C}, 10 \mathrm{~min}$. can be separated by extraction from the aqueous reaction mixture, it was investigated that the catalyst could be recovered by filtration and reused for the oxidation of a fresh batch of cinnamaldehyde. Table 2 provides a summary of the recyclability properties of the MWCNTs-g-CD. After each reaction, the benzaldehyde was isolated by extraction, and the resulting precipitate was washed sequentially with ethanol and water at $80{ }^{\circ} \mathrm{C}$ for $2 \mathrm{~h}$. After drying, the catalyst was reused for the next run under the same conditions. As shown in Table 2, the MWCNTs-g-CD shows outstanding recyclability over five catalytic cycles, as well as good stability.

Scanning electron microscope (SEM) was used to evaluate changes in the morphological characteristics and sizes of the used catalysts. SEM images of the MWCNTs and the used MWCNTs-g-CD are shown in Fig. 8. The MWCNTs were found to be tubular in shape with a diameter in the range of 10-30 nm (Fig. 8(a)). In contrast, the diameters of the used MWCNTs-g-CD (20-40 nm) were larger than those of the MWCNTs, which indicated that $\beta$-CD was uniformly dispersed on the surfaces of the MWCNTs (Fig. 8(b)). This difference in the diameters was attributed to chemical bonding between the MWCNTs and $\beta$-CD, and hydrogen-bonding interactions between the adjacent $\beta$-CD molecules. A comparison of the SEM images for the MWCNTs and the used MWCNTs-g-CD confirmed that the morphological characteristics of the used MWCNTs-g-CD were not affected by the oxidation of cinnamaldehyde.

\subsection{The oxidation of substituted cinnamaldehydes}

In light of the results achieved for the efficient oxidation of

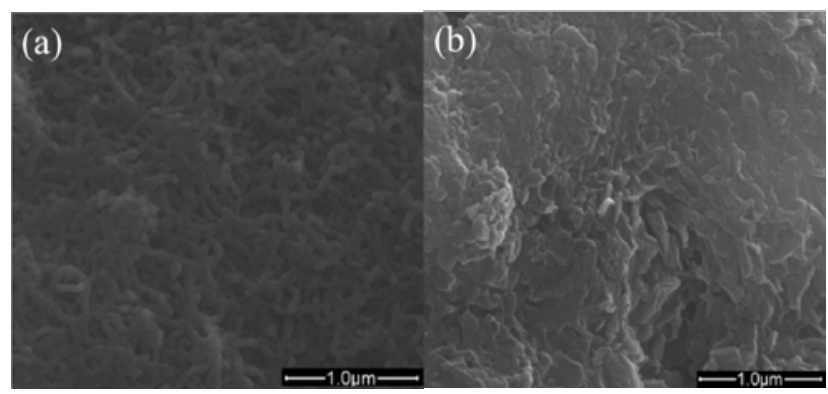

Fig. 8. SEM images of MWCNTs (a) and the used MWCNTs-g-CD (b). 
cinnamaldehyde, we also evaluated the oxidation of a series of substituted cinnamaldehydes using the MWCNTs-g-CD catalyst, and the results are listed in Table 3. Pleasingly, all of the substituted cinnamaldehydes were smoothly converted to the corresponding benzaldehydes with good conversions and selectivity. However, the electronic nature of the substituent group had a pronounced impact on the outcome of the oxidation reaction. For example, cinnamaldehydes bearing an oxygen-containing substituent (Table 3 , entries 1-3 and 10-12) produced the corresponding benzaldehydes in $81 \%-85 \%$ selectivity, which were higher than that of cinnamaldehyde. This increase in the selectivity could be attributed to the formation of a weak ternary complex between the oxygen-containing substituent (e.g., $-\mathrm{OCH}_{3}$ or $-\mathrm{NO}_{2}$ ) and the secondary hydroxyl groups on the rim of the $\beta$-CD through hydrogen bonding interactions. The position of the substituent on the phenyl ring had a considerable impact on the catalytic activity through steric hindrance. For example, the conversions of the cinnamal-

\section{Table 3}

Oxidation of substituted cinnamaldehydes to the corresponding aldehydes over MWCNTs-g-CD.

\begin{tabular}{|c|c|c|c|c|c|}
\hline $\begin{array}{l}\text { En- } \\
\text { try }\end{array}$ & Reactant & Product & $\begin{array}{c}\text { Reaction } \\
\text { time } \\
\text { (min) }\end{array}$ & $\begin{array}{c}\text { Con- } \\
\text { version } \\
(\%) \\
\end{array}$ & $\begin{array}{c}\text { Selec- } \\
\text { tivity } \\
(\%) \\
\end{array}$ \\
\hline 1 & & & 10 & 100 & 84 \\
\hline 2 & & & 10 & 96 & 84.5 \\
\hline 3 & & & 10 & 93 & 85 \\
\hline 4 & & & 15 & 97 & 72 \\
\hline 5 & & & 15 & 94 & 76 \\
\hline 6 & & & 15 & 92 & 78 \\
\hline 7 & & & 180 & 78 & 72 \\
\hline 8 & & & 180 & 71 & 74 \\
\hline 9 & & & 180 & 65 & 76 \\
\hline 10 & & & 180 & 75 & 81 \\
\hline 11 & & & 180 & 68 & 82 \\
\hline 12 & & & 180 & 63 & 84 \\
\hline
\end{tabular}

dehydes increased going from the $o$-substituted systems (Table 3 , entries $1,4,7$ and 10 ) to the $m$-substituted systems (entries $2,5,8$ and 11), and increased again going to the $p$-substituted cinnamaldehydes (Table 3, entries 3, 6, 9 and 12). These results also indicated that the oxidation of the substituted cinnamaldehydes was also affected by the $\beta$-CD cavity. Cinnamaldehydes bearing an electron-rich methoxy group (Table 3, entries 1-3) or an electron-neutral methyl group (Table 3, entries 4-6) gave the corresponding benzaldehydes in $63 \%-100 \%$ conversions with selectivities of $72 \%-85 \%$. In contrast, cinnamaldehydes bearing an electron-withdrawing chloride- or nitro-substituent gave conversions and selectivities of $63 \%-78 \%$ and $72 \%-85 \%$, respectively, (Table 3, entries 6-12) even after a longer reaction time (180 $\mathrm{min})$. The results in Table 3 also showed that the formation of weak interactions between $\beta-C D$ and the substrates enhanced their reactivity depending on the size, shape and hydrophobicity of the guest molecule $[3,56]$.

\subsection{Reaction mechanism}

Our previous results $[21-23,41]$ indicated that the $\beta-C D$ sites could be regarded as the active sites in the catalytic oxidation of cinnamaldehyde with $\mathrm{H}_{2} \mathrm{O}_{2}$ activated by bicarbonate ions in water. Based on the experimental data presented above, we proposed a plausible mechanism for this reaction, which is presented in Fig. 9. Firstly, cinnamaldehyde would be quickly adsorbed onto the surface of the MWCNTs through electrostatic attraction under mechanical stirring (Fig. 10). Cinnamaldehyde would also be encapsulated in the cavities of $\beta$-CD through host-guest interactions. However, the changes observed in the energy during the course of the inclusion process would be dependent of the stability of the host-guest complexes between the MWCNT or $\beta$-CD and the different guests. Previous reports in this area have indicated that increasingly negative binding energies lead to increasingly stable host-guest complexes [41]. The binding energy for the MWCNT-cinnamaldehyde complex is listed in Table 4. The results showed that the MWCNTs could interact with cinnamaldehyde to form stable inclusion complex through aromatic-aromatic $(\pi-\pi$ stacking) interactions [57]. However, the binding energy for the cinnamaldehyde- $\beta$-CD complex was lower than that of the MWCNT-cinnamaldehyde complex [8], indicating that cinnamaldehyde was being preferentially absorbed in the $\beta$-CD cavities. The $\beta$-CD sites therefore interacted with cinnamaldehyde to form more stable inclusion complex than the MWCNTs through intermolecular hydrogen bond interactions, which were confirmed by ${ }^{1} \mathrm{H}$ NMR and 2D ROESY experiments [11]. Secondly, the nucleophilic hydroxyl groups of $\beta$-CD would attack the $\beta$-carbon atom of the $\alpha, \beta$-unsaturated carbocation to form a hydrated molecule via the hydrolysis of sodium carbonate. This would lead to a $6 \%$ yield of benzaldehyde by the deprotonation of the hydrated molecule, which would lead to the cleavage of the $\mathrm{C}=\mathrm{C}$ bond. In contrast, the active peroxymonocarbonate ions $\left(\mathrm{HCO}_{4}^{-}\right.$) formed via the activation of $\mathrm{H}_{2} \mathrm{O}_{2}$ with bicarbonate would be adsorbed onto the surfaces of the MWCNTs. The MWCNTs could also accelerate the formation of the active species according to reaction (2). The $\mathrm{HCO}_{4}^{-}$species 


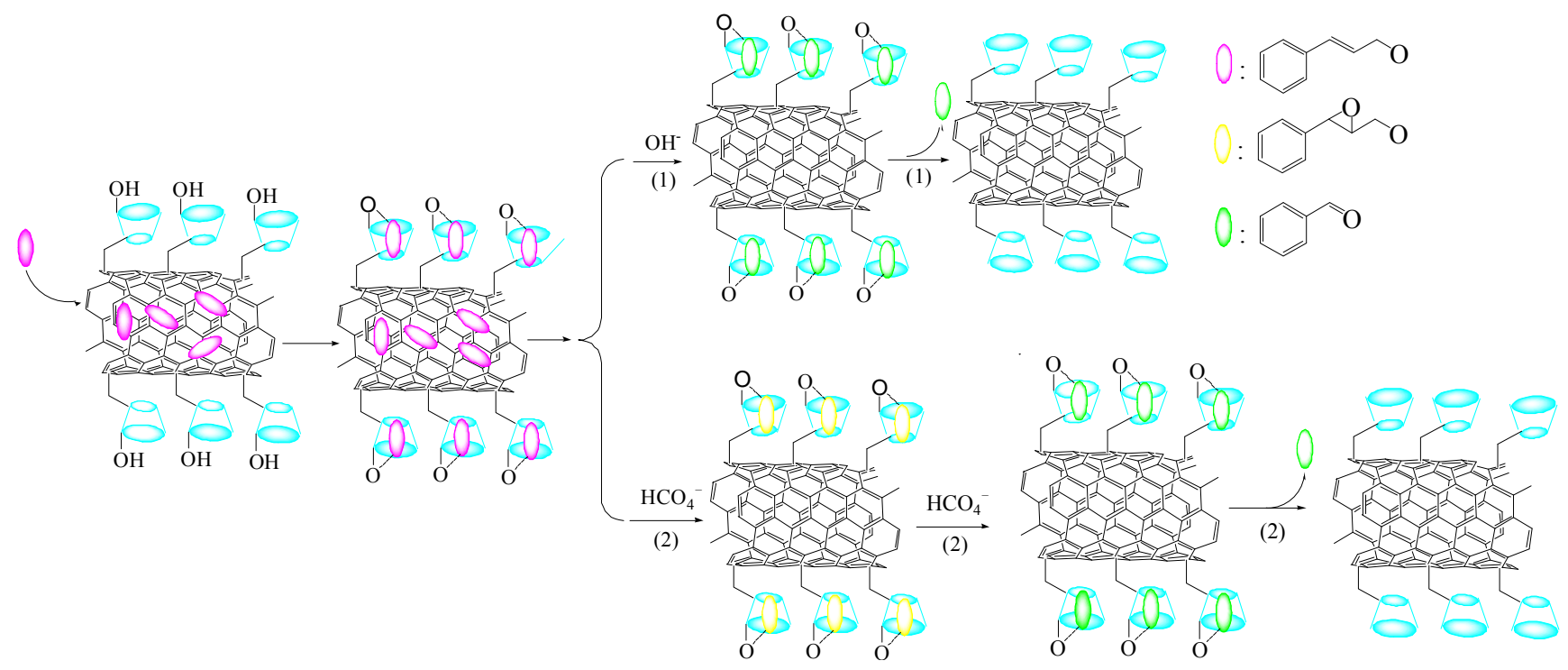

Fig. 9. Proposed mechanism for the oxidation of cinnamaldehyde over MWCNTs-g-CD.

generated in this way could react with cinnamaldehyde to yield the corresponding epoxide. In situ-generated $\mathrm{HCO}_{4}{ }^{-}$could then react with newly formed epoxide to form the benzaldehyde. The catalyst would then be restored to its initial state.

$$
\begin{aligned}
\mathrm{HCO}_{3}{ }^{-}+\mathrm{H}_{2} \mathrm{O} & =\mathrm{H}_{2} \mathrm{CO}_{3}+\mathrm{OH}^{-} \\
\mathrm{HCO}_{3}{ }^{-}+\mathrm{H}_{2} \mathrm{O}_{2} & =\mathrm{HCO}_{4}{ }^{-}+\mathrm{H}_{2} \mathrm{O}
\end{aligned}
$$

Lastly, we evaluated oxidation of cinnamaldehyde over $\beta-\mathrm{CD}$ and MWCNTs-g-CD based on the apparent activation energy $\left(E_{a}\right)$. The results revealed that the rate constants increased with the increasing temperature, and that the rate constants were higher in the presence of MWCNTs-g-CD than they were in the absence of $\beta$-CD, which implied that MWCNTs-g-CD could significantly improve the oxidation reaction (Table 5). The relationship between the rate constant and the temperature was fitted according to the following equation:
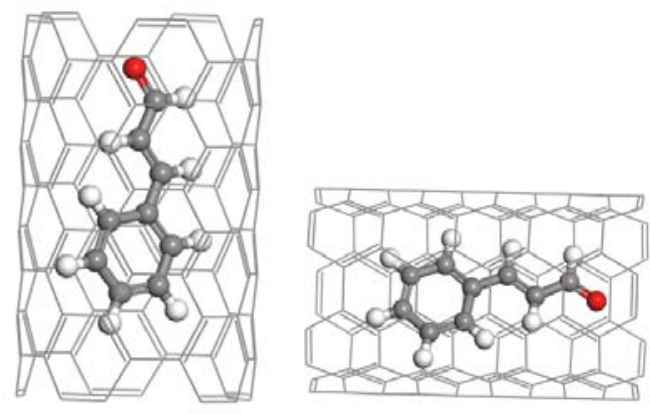

Fig. 10. Minimum energy structures of MWCNT-cinnmaldehyde complex calculated by DMol3.

Table 4

Energies in the inclusion complexation of host-guests calculated by DMol3.

\begin{tabular}{lcc}
\hline Entry & $\begin{array}{c}\text { Energy } \\
(\mathrm{kJ} / \mathrm{mol})\end{array}$ & $\begin{array}{c}\text { Binding energy } \\
(\Delta E, \mathrm{~kJ} / \mathrm{mol})\end{array}$ \\
\hline MWCNT & -23074523.92 & - \\
Cinnmaldehyde & -1100811.63 & - \\
MWCNT -Cinnmaldehyde & -24175344.63 & -9.08 \\
\hline
\end{tabular}

$$
k=k_{0} \exp \left(-E_{\mathrm{a}} / R T\right)
$$

where $k$ is the rate constant of the reaction $\left(\mathrm{min}^{-1}\right), k_{0}$ is the constant-frequency factor $\left(\mathrm{min}^{-1}\right), E_{\mathrm{a}}$ is the activation energy of the reaction $(\mathrm{kJ} / \mathrm{mol}), R$ is the gas constant $\left(8.314 \times 10^{-3}\right.$ $\mathrm{kJ} \mathrm{mol}^{-1} \mathrm{~K}^{-1}$ ), and $T$ is the absolute temperature (K).

The rate constants shown in Table 5 were used to generate the Arrhenius plots of $\ln k$ and $1 / T$ shown in Fig. 11 . The $E_{\text {a val- }}$ ues were calculated in the presence of the MWCNTs-g-CD and $\beta$-CD and found to be 16.33 and $45.66 \mathrm{~kJ} / \mathrm{mol}$, respectively. These results clearly show that the MWCNTs-g-CD led to a reduction in the activation energy and improved the oxidation

\section{Table 5}

The rate orders and rate constants at various reaction temperatures in the presence of $\beta-C D$ and MWCNTs-g-CD.

\begin{tabular}{lccccc}
\hline & \multicolumn{2}{c}{$\beta$-CD } & & \multicolumn{2}{c}{ MWCNTs-g-CD } \\
\cline { 2 - 3 } \cline { 5 - 6 }$T(\mathrm{~K})$ & $\begin{array}{c}k \\
\left(\mathrm{~min}^{-1}\right)\end{array}$ & $\begin{array}{c}\text { Correlation } \\
\text { coefficient }\left(R^{2}\right)\end{array}$ & & $\begin{array}{c}k \\
\left(\mathrm{~min}^{-1}\right)\end{array}$ & $\begin{array}{c}\text { Correlation } \\
\text { coefficient }\left(R^{2}\right)\end{array}$ \\
\hline 303 & 0.00614 & 0.9921 & & 0.1847 & 0.9867 \\
313 & 0.01236 & 0.9945 & & 0.2225 & 0.9789 \\
323 & 0.02280 & 0.9978 & & 0.2637 & 0.9912 \\
333 & 0.03050 & 0.9961 & & 0.3345 & 0.9812 \\
\hline
\end{tabular}

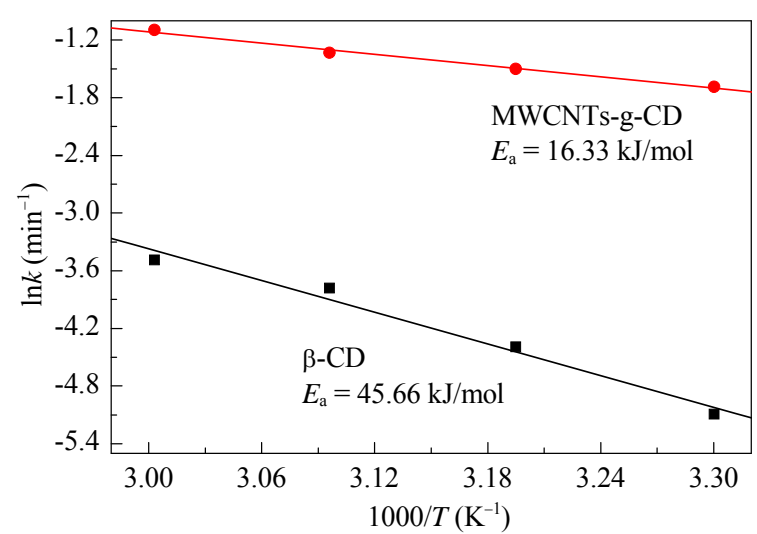

Fig. 11. Arrhenius plots for cinnamaldehyde oxidation. 
rate of cinnamaldehyde compared with $\beta$-CD. In addition, the inclusion of $\beta$-CD led to an increase in the substrate specificity and mass transfer, as reported previously [22]. Taken together with the synergistic effects of MWCNTs and $\beta$-CD, these results highlight the potential of MWCNTs-g-CD for the oxidation of cinnamaldehyde.

\section{Conclusions}

An efficient $\beta$-cyclodextrin ( $\beta$-CD)-functionalized MWNT (MWCNTs-g-CD) catalyst was designed and successfully applied to the eco-friendly oxidation of cinnamaldehyde to benzaldehyde. Under the optimized conditions, this system achieved $95 \%$ cinnamaldehyde conversion with $85 \%$ selectivity to the natural benzaldehyde with a short reaction time of 10 min. This catalyst also demonstrated outstanding recyclability following five reaction cycles, with good stability. These results highlight the potential of designing heterogeneous catalysts for the production of natural benzaldehyde.

\section{References}

[1] F. A. Jury, I. Polaert, L. B. Pierella, L. Estel, Catal. Commun., 2014, 46, 6-10.

[2] R. B. Cang, B. Lu, X. P. Li, R. Niu, J. X. Zhao, Q. H. Cai, Chem. Eng. Sci., 2015, 137, 268-275.

[3] Z. J. Yang, X. Zhang, X. D. Yao, Y. X. Fang, H. R. Chen, H. B. Ji, Tetrahedron, 2016, 72, 1773-1781.

[4] X. C. Zhu, R. W. Shen, L. X. Zhang, Chin. J. Catal., 2014, 35, 1716-1726.

[5] L. Ma, L. Jia, X. F. Guo, L. J. Xiang, Chin. J. Catal., 2014, 35, 108-119.

[6] J. G. Cui, C. S. Wang, J. Q. Ma, X. H. Liao, Chem. World, 2002, 315-317.

[7] A. O. Pittet, R. Muralidhara, A. L. Liberman, US Patent 4683342A, 1987.

[8] H. R. Chen, H. B. Ji, AIChE J., 2010, 56, 466-476.

[9] H. R. Chen, H. B. Ji, X. T. Zhou, L. F. Wang, Tetrahedron, 2010, 66, 9888-9893.
[10] H. R. Chen, H. B. Ji, L. F. Wang, Fine Chem., 2010, 27, 579-583.

[11] H. R. Chen, H. B. Ji, X. T. Zhou, J. Xu, L. F. Wang, Catal. Commun., 2009, 10, 828-832.

[12] G. S. Chen, M. Jiang, Chem. Soc. Rev., 2011, 40, 2254-2266.

[13] G. Crini, Chem. Rev., 2014, 114, 10940-10975.

[14] E. M. M. Del Valle, Process Biochem., 2004, 39, 1033-1046.

[15] K. Takahashi, Chem. Rev., 1998, 98, 2013-2034.

[16] K. Surendra, N. S. Krishnaveni, M. A. Reddy, Y. V. D. Nageswar, K. R. Rao, J. Org. Chem., 2003, 68, 2058-2059.

[17] A. Kumar, V. D. Tripathi, P. Kumar, Green Chem., 2011,13, 51-54.

[18] K. Surendra, N. S. Krishnaveni, V. P. Kumar, R. Sridhar, K. R. Rao, Tetrahedron Lett., 2005, 46, 4581-4583.

[19] N. S. Krishnaveni, K. Surendra, K. Rama Rao, Adv. Synth. Catal., 2004, 346, 346-350.

[20] J. Shankar, K. Karnakar, B. Srinivas, Y. V. D. Nageswar, Tetrahedron Lett., 2010, 51, 3938-3939.

[21] Z. J. Yang, H. Zeng, X. T. Zhou, H. B. Ji, Supramol. Chem., 2013, 25, 233-245.

[22] Z. J. Yang, H. Zeng, X. T. Zhou, H. B. Ji, Tetrahedron, 2012, 68, 5912-5919.

[23] Z. J. Yang, H. G. Jiang, X. T. Zhou, Y. X. Fang, H. B. Ji, Supramol. Chem., 2012, 24, 379-384.

[24] Z. J. Yang, H. B. Ji, Chin. J. Catal., 2014, 35, 590-598.

[25] G. P. Rao, C. Lu, F. Su, Sep. Purif. Technol., 2007, 58, 224-231.

[26] A. Peigney, C. Laurent, E. Flahaut, R. R. Bacsa, A. Rousset, Carbon, 2001, 39, 507-514.

[27] D. Q. Yang, J. F. Rochette, E. Sacher, J. Phys. Chem. B, 2005, 109, 4481-4484.

[28] J. P. Salvetat, J. M. Bonard, N. H. Thomson, A. J. Kulik, L. Forró, W. Benoit, L. Zuppiroli, Appl. Phys. A, 1999, 69, 255-260.

[29] B. Pan, B. S. Xing, Environ. Sci. Technol., 2008, 42, 9005-9013.

[30] C. Lu, Y. L. Chung, K. F. Chang, Water Res., 2005, 39, 1183-1189.

[31] J. Luo, F. Peng, H. Yu, H. J. Wang, W. X. Zheng, ChemCatChem, 2013, 5, 1578-1586.

[32] S. X. Yang, X. Li, W. P. Zhu, J. B. Wang, C. Descorme, Carbon, 2008, $46,445-452$

[33] Z. K. Zhao, Y. T. Dai, G. F. Ge, G. R. Wang, ChemCatChem, 2015, 7, $1135-1144$.

[34] Z. K. Zhao, Y. T. Dai, G. F. Ge, G. R. Wang, AIChE J., 2015, 61, 2543-2561.

\section{Graphical Abstract}

Chin. J. Catal., 2016, 37: 2086-2097 doi: 10.1016/S1872-2067(16)62543-3

\section{Efficient oxidation of cinnamon oil to natural benzaldehyde over $\beta$-cyclodextrin-functionalized MWCNTs}

Zujin Yang, Xia Zhang, Yanxiong Fang, Zebao Rui*, Hongbing Ji* Sun Yat-sen University; Guangdong University of Technology

$\beta$-cyclodextrin ( $\beta$-CD) functionalized MWNTs (MWCNTs-g-CD) were designed for the oxidation of cinnamon oil to natural benzaldehyde in the aqueous solutions. The synergistic effect between MWCNTs and $\beta$-CD leads to the remarkably enhanced performance of MWCNTs-g-CD for the catalytic oxidation of cinnamaldehyde.

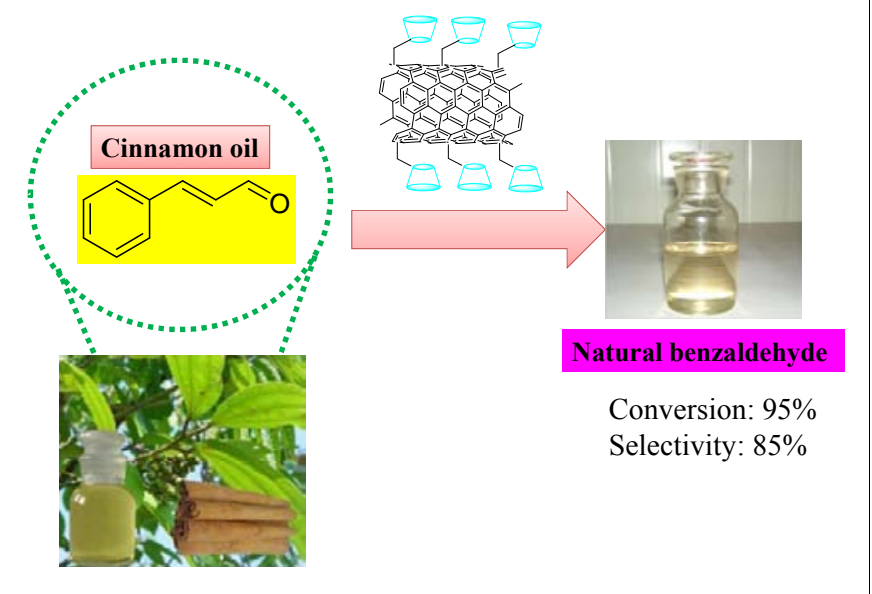


[35] J. Luo, F. Peng, H. Yu, H. J. Wang, Chem. Eng. J., 2012, 204-206, 98-106.

[36] J. Luo, H. Yu, H. J. Wang, H. H. Wang, F. Peng, Chem. Eng. J., 2014, $240,434-442$.

[37] Y. X. Zhang, C. L. Chen, L. X. Peng, Z. S. Ma, Y. J. Zhang, H. H. Xia, A. L. Yang, L. Wang, D. S. Su, J. Zhang, Nano Res., 2015, 8, 502-511.

[38] N. G. Sahoo, S. Rana, J. W. Cho, L. Li, S. H. Chan, Prog. Polym. Sci,, 2010, 35, 837-867.

[39] H. N. Hareesh, K. U. Minchitha, N. Nagaraju, N. Kathyayini, Chin. J. Catal., 2015, 36, 1825-1836.

[40] C. Gouveia-Caridade, R. Pauliukaite, C. M. A. Brett, Electrochim. Acta., 2008, 53, 6732-6739.

[41] Z. J. Yang, H. B. Ji, ACS Sustain. Chem. Eng., 2013, 1, 1172-1179.

[42] B. Delley, J. Chem. Phys., 1990, 92, 508-517.

[43] H. Q. Dong, Y. Y. Li, J. H. Yu, Y. Y. Song, X. J. Cai, J. Q. Liu, J. M. Zhang, R. C. Ewing, D. Shi, Small, 2013, 9, 446-456.

[44] W. Liu, Z. Shadike, Z. C. Liu, W. Y. Liu, J. Y. Xie, Z. W. Fu, Carbon, 2015, 93, 523-532.

[45] G. Alarcón-Angeles, B. Pérez-López, M. Palomar-Pardave, M. T. Ramírez-Silva, S. Alegret, A. Merkoçi, Carbon, 2008, 46, 898-906.

[46] T. A. Saleh, S. Agarwal, V. K. Gupta, Appl. Catal. B, 2011, 106, 46-53.
[47] A. Z. M. Badruddoza, A. S. H. Tay, P. Y. Tan, K. Hidajat, M. S. Uddin, J. Hazard. Mater., 2011, 185, 1177-1186.

[48] S. P. Zhang, B. Liu, C. Y. Li, W. Chen, Z. J. Yao, D. T. Yao, R. B. Yu, H. O. Song, Chin. Chem. Lett., 2014, 25, 355-358.

[49] M. R. Karim, C. J. Lee, M. S. Lee, J. Polym. Sci. A, 2006, 44, 5283-5290.

[50] D. D. Shao, G. D. Sheng, C. L. Chen, X. K. Wang, M. Nagatsu, Chemosphere, 2010, 79, 679-685.

[51] Z. J. Yang, J. P. Liu, X. D. Yao, Z. B. Rui, H. B. Ji, Sep. Purif. Technol,, 2016, 158, 417-421.

[52] J. G. Yu, D. S. Huang, K. L. Huang, H. Yong, Chin. J. Chem., 2011, 29, 893-897.

[53] H. R. Yao, D. E. Richardson, J. Am. Chem. Soc., 2003, 125, 6211-6221.

[54] H. R. Yao, D. E. Richardson, J. Am. Chem. Soc., 2000, 122, 3220-3221.

[55] D. E. Richardson, H. R. Yao, K. M. Frank, D. A. Bennett, J. Am. Chem. Soc., 2000, 122, 1729-1739.

[56] L. Shao, C. Z. Mu, H. P. Du, Z. Czech, H. C. Du, Y. P. Bai, Appl. Surf. Sci., 2011, 258, 1682-1688.

[57] E. S. Alldredge, Ş. C. Bădescu, N. Bajwa, F. K. Perkins, E. S. Snow, T. L. Reinecke, Phys. Rev. B, 2010, 82, 2951-2957.

\section{$\boldsymbol{\beta}$-环糊精功能化碳纳米管高效催化氧化肉桂油制备天然苯甲醛

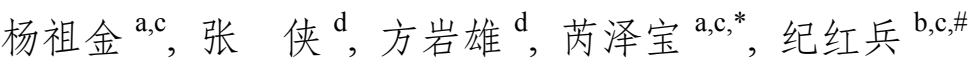 \\ ${ }^{\mathrm{a}}$ 中山大学化学工程与技术学院, 广东广州 510275 \\ ${ }^{\mathrm{b}}$ 中山大学化学学院, 广东广州 510275 \\ ${ }^{c}$ 中山大学惠州研究院, 广东惠州 516216
} \\ d广东工业大学轻化工学院, 广东广州 510006}

摘要: 天然苯甲醛是一类重要的食品添加剂. 在温和液相反应条件下催化氧化肉桂醛制天然苯甲醛是一个有效的手段, 但 该过程需要活性高、选择性好和易循环利用的高效催化剂.

环糊精 $(\mathrm{CD})$ 一般是由 6-8 个 D-吡喃葡萄糖单元构成, 具有 “内疏水、外亲水”的特殊结构, 能够与尺寸和形状相近的分 子通过分子间的非共价键作用力 (如氢键、范德华力及疏水性作用力) 形成主客体分子包结物. 利用环糊精模拟天然酶来 提高反应活性和产物选择性一直是研究者追求的目标, 并已被广泛用于调控不同的有机反应过程, 如氧化、还原、水解和 开环等反应. 然而, 由于 $\beta$-环糊精易溶于水, 需要将其固载至合适的载体上才能实现其循环重复利用. 近年, 文献中报道了 将 $\beta$-环糊精固定至纤维素或壳聚糖用于催化肉桂油制天然苯甲醛, 结果表明, 环糊精与载体的功能基团通过弱相互作用的 协同能明显提高肉桂醛氧化性能. 然而, 从实际应用角度看, 这些催化剂的循环使用性能和机械强度还需进一步增强.

碳纳米管具有良好的化学稳定性、较强的机械性能和环境兼容性, 广泛应用于液相吸附或反应系统. 例如, 碳纳米管作 为一种无金属催化剂被成功用于芳族烃和烷烃的氧化脱氢、氧还原反应、烃或酚的氧化和氨分解以及催化苯甲醇制备苯 甲醛等反应体系中.

基于环糊精能通过形成主客体包结物的形式明显提高反应选择性, 以及多壁碳纳米管能通过形成共轭配合物的形式 对溶液中芳香化合物具有良好的吸附能力, 本文制备了一种 $\beta$-环糊精功能化多壁碳纳米管, 并将其成功用于溶液中肉桂油 催化氧化制天然苯甲醛的反应. $\beta$-环糊精功能化碳纳米管表现出比环糊精聚合物催化剂更优异的催化性能, 在 $10 \mathrm{~min}$ 内, 肉桂醛转化率和天然苯甲醛选择性能分别达到 $95 \%$ 和 $85 \%$, 并且反应体系的活化能从 $45.66 \mathrm{~kJ} / \mathrm{mol}$ 降至 $16.33 \mathrm{~kJ} / \mathrm{mol}$. 循 环使用结果显示, 这种复合催化剂还具有良好的稳定性和可循环使用性. 利用拉曼光谱、透射电镜、红外光谱、X 射线衍 射、比表面积和热重分析对催化剂进行了系统表征. 结果表明, 多壁碳纳米管和 $\beta$-环糊精的协同催化作用是其具有高效催 化性能的重要原因.

为了进一步研究其催化反应机理, 利用量子化学计算对主客体之间的相互作用力进行了探究. 结果表明, 肉桂醛易通 过电子相互作用力吸附至碳纳米管表面, 由于环糊精空腔的弱相互作用力更强, 肉桂醛更容易进入环糊精空腔, 通过环糊 精上的羟基与肉桂醛之间 $\mathrm{O}-\mathrm{H} \cdots \mathrm{O}$ 的氢键相互作用, 并通过体系生成的高碳酸根氧化剂 $\left(\mathrm{HCO}_{4}{ }^{-}\right)$, 促使肉桂醛 $\mathrm{C}=\mathrm{C}$ 不饱和 双键断裂生成苯甲酫, 而生成的苯甲酫与环糊精之间的弱相互作用低于肉桂醛与环糊精之间的相互作用, 苯甲醛可迅速地 离开环糊精空腔. 因而, $\beta$-环糊精和碳纳米管的协同作用可明显提高底物选择性. 
关键词: $\beta$-环糊精; 肉桂油; 选择性氧化; 苯甲醛; 多壁碳纳米管; 协同效应

收稿日期: 2016-07-20. 接受日期: 2016-09-01. 出版日期: 2016-15-05.

*通讯联系人. 电话: (020)84113663; 电子信箱: ruizebao@mail.sysu.edu.cn

\#通讯联系人. 电话: (020)84113658; 电子信箱: jihb@mail.sysu.edu.cn

基金来源：国家自然科学基金 (21376279,21276102,21425627); 广东省热敏性精细化学品合成与分离工程研究中心 (2015B090903061); 中央高校基本科研业务费专项资金 (14lgpy28), 广州市科技计划 (2014J4100125).

本文的英文电子版由Elsevier出版社在ScienceDirect上出版(http://www.sciencedirect.com/science/journal/18722067). 